\title{
Studi Kasus Ketidakpatuhan Orang Kontak Serumah terhadap Anjuran Pemeriksaan Tuberkulosis
}

\author{
Herawati ${ }^{1}$, Rovina Ruslami², Ahmad Yamin ${ }^{3}$ \\ ${ }^{1}$ PSIK Fakultas Kedokteran Universitas Lambung Mangkurat, ${ }^{2}$ Fakultas Kedokteran Universitas \\ Padjadjaran-RSHS, ${ }^{3}$ Fakultas Keperawatan Universitas Padjadjaran \\ E-mail: nabila_sholehah
}

\begin{abstract}
Abstrak
Ketidakpatuhan orang kontak serumah terhadap anjuran pemeriksaan Tuberkulosis (TB) merupakan fenomena kompleks, dinamis dari faktor yang berkaitan dengan perilaku. Penelitian ini bertujuan untuk menggali perilaku ketidakpatuhan orang kontak serumah terhadap anjuran pemeriksaan TB dengan menggunakan Health Belief Model (HBM). Penelitian ini adalah studi kasus yang dilakukan di Kelurahan Pajajaran Kota Bandung. Subjek penelitian adalah sembilan orang kontak serumah dan enam orang perawat Puskesmas Pasirkaliki. Pengumpulan data dilakukan dengan studi dokumentasi, observasi pasif tidak berstruktur, wawancara mendalam, dan diskusi kelompok terarah. Data dianalisis dengan menggunakan model Miles dan Huberman, yaitu reduksi data, penyajian data, dan penarikan kesimpulan. Hasil penelitian meliputi persepsi kerentanan, persepsi keseriusan, persepsi manfaat pemeriksaan orang kontak serumah, dan isyarat untuk melakukan tindakan berdasarkan HBM. Persepsi orang kontak serumah tentang kerentanan TB meliputi adanya perasaan takut tertular, melakukan pemisahan, dan menerima takdir. Persepsi orang kontak serumah mengenai keseriusan penyakit TB yaitu kematian, perasaan malu atau minder. Persepsi orang kontak serumah tentang manfaat skrining yaitu akan diketahui apakah orang kontak serumah terkena TB atau tidak. Isyarat untuk melakukan tindakan pemeriksaan TB menurut orang kontak serumah yaitu apabila mereka sudah sakit atau muncul gejala-gejala TB. Hasil penelitian dari perawat menunjukkan bahwa perawat mengetahui bahwa salah satu standar program penanggulangan TB (P2TB) adalah pemeriksaan TB pada orang kontak serumah penderita TB paru terutama yang basil tahan asam (BTA) positif dan anak dengan TB. Pemeriksaan TB tersebut dilakukan dengan pemeriksaan dahak sewaktu-pagi-sewaktu (SPS). Persepsi perawat mengenai hambatan dalam menjalankan peran dan fungsinya yaitu adanya keterbatasan jumlah tenaga di puskesmas, pendidikan perawat masih rendah, dan perawat mendapat tugas limpahan di klinik.
\end{abstract}

Kata kunci: Ketidakpatuhan, kontak serumah, pemeriksaan TB, studi kualitatif.

\section{Case Study of Non-Adherence of Household Contacts toward Tuberculosis Screening}

\begin{abstract}
Non-adherence of household contacts to undergo screening for Tuberculosis (TB) is a dynamic and complex phenomenon of the various factors related to behaviour. The objective of this study was to explore the behaviours related to non-adherence of household contacts to undergo screening for TB. This study is a descriptive case study that was conducted at the Pajajaran village, Bandung city. Participant were 9 household contacts of smear positive TB patients and 6 nurses who is working in the Pasirkaliki Community Health Center (CHC). Data collection was performed with the study documentation, non-structured passive observation, in-depth interview, and focus group discussion (FGD). Data analysis was according to Miles and Huberman model, which consist of data reduction, data display and drawing conclusions. The result includes perception of vulnerability of TB, perceptions of seriousness of TB, perceptions of benefits of TB screening, and cues to action for the TB patients household contact. The result showed that perceptions of the household contact of TB vulnerability were: fear of infection, make the separation and accept fate. Perceptions of the seriousness of TB were that TB could cause death and feelings of shame or inferiority. As for the perception of benefits was by doing screening, it will be known whether household contacts are exposed to TB or not. While the cues to action for household contact to perform screening for TB was if they are sick or have emerging symptoms of TB. The nurses knew that according to P2TB (TB management program) standards, the household contacts of TB patients should undergo screening for TB, especially for smear-positive pulmonary TB patients and paediatric TB. They knew that TB screening was done through sputum smear microscopy. Nurses' perceptions about the barriers in carrying out their role and function were limited number of human resources in $\mathrm{CHC}$, lack of education, and the presence of abundance tasks at the clinic.
\end{abstract}

Key words: Household contact, non-adherence, qualitative study, TB screening. 
Herawati : Studi Kasus Ketidakpatuhan Orang Kontak Serumah

\section{Pendahuluan}

Tuberkulosis (TB) menduduki peringkat ketiga penyakit infeksi dan merupakan salah satu masalah kesehatan masyarakat. Sejak tahun 1993, World Health Organization (WHO) menyatakan bahwa TB merupakan kegawatdaruratan global bagi kemanusiaan (Depkes, 2006). Diperkirakan hampir seper-tiga penduduk dunia terinfeksi oleh mycobacterium tuberculosis (Depkes, 2007), maka perlu upaya atau program penanggulangan TB (P2TB).

Penemuan penderita TB merupakan langkah pertama dalam kegiatan P2TB. Kegiatan ini akan dapat menurunkan kesakitan dan kematian akibat TB, juga merupakan kegiatan pencegahan penularan TB yang paling efektif di masyarakat (Depkes, 2007). Ketidakadekuatan penemuan penderita dan penanganannya merupakan penghalang utama dalam pengendalian TB (Cramm, Harry, Moller, \& Anna, 2010).

Orang kontak serumah dengan penderita TB terutama mereka yang BTA positif dan pada keluarga dengan anak yang menderita TB, harus dilakukan pemeriksaan TB dengan diperiksakan dahaknya (Depkes, 2007). Hasil penelitian Boon dan Verver (2008), menyatakan bahwa risiko terkena gejala atau tertular pada orang kontak serumah dengan penderita TB sangat tinggi, terutama jika daya tahan tubuh mereka kurang baik, sehingga menyarankan bahwa pemeriksaan kontak serumah akan sangat berarti dalam meningkatkan angka cakupan penemuan kasus untuk penyakit TB.

Perawat komunitas dapat melakukan kunjungan kepada penderita TB atau orang yang diduga menderita TB dengan menjelaskan tentang TB dan kemungkinan menderita TB (Toth, Fackellman, Piggot, \& Tolomeo, 2004). Hasil penelitian Gonzalez, dkk. (2009) di Cuba menyebutkan bahwa penemuan penderita TB secara aktif yang diintegrasikan dengan kunjungan rumah, akan membantu untuk menemukan penderita yang mungkin tidak terdeteksi pada penemuan secara pasif di tingkat pelayanan kesehatan.

Kepatuhan seseorang dalam penanganan TB adalah mencakup semua aspek untuk mengikuti sesuai dengan saran atau anjuran petugas kesehatan. Pengetahuan dan persepsi seseorang akan berpengaruh terhadap kepatuhan mengikuti prosedur ini, sedangkan ketidakpatuhan merupakan suatu fenomena yang kompleks, dinamis dari berbagai faktor yang berkaitan dengan perilaku.

Para peneliti yang telah melakukan analisis perilaku manusia dan kesehatan telah mengembangkan teori-teoriyang menjelaskan faktor-faktor dan interaksi di antara faktorfaktor yang memengaruhi kesehatan individu atau sekelompok individu, diantaranya adalah teori model kepercayaan kesehatan atau health belief model (HBM) (Maville \& Huerta, 2008). Teori HBM merupakan salah satu teori yang paling sering digunakan dalam banyak studi tentang perilaku kesehatan (Painter, dkk., 2008). Teori HBM mengandung beberapa konsep dasar yang memprediksi seseorang akan berperilaku dalam mencegah, melakukan skrining, atau untuk mengontrol kondisi kesakitan. Hal ini mencakup kerentanan, keseriusan, manfaat dan hambatan untuk berperilaku, alasan untuk melakukan tindakan dan kemampuan diri untuk melakukan tindakan (Dorthe, Lise, Torsten, \& Kristi, 2009).

Hasil pengamatan di Kelurahan Pajajaran Kecamatan Cicendo Wilayah Kerja Puskesmas Pasirkaliki diperoleh data bahwa pada Bulan Januari 2011, sebanyak 74,6\% dari 30 orang kontak serumah dengan penderita TB belum melakukan pemeriksaan TB ke puskesmas. Saat ditanyakan alasan belum melakukan pemeriksaan TB, sebagian mengatakan merasa masih sehat dan belum muncul gejalagejala seperti penderita TB. Pada sebagian yang lain mengatakan mengalami keluhan batuk-batuk berdahak sudah lebih dari 2 minggu. Batuk yang dirasakan merupakan batuk pilek biasa, sehingga tidak memerlukan pemeriksaan dahak ke puskesmas. Alasan lain yang dikemukakan terkait belum dilakukan pemeriksaan TB karena tidak ada biaya transportasi untuk berangkat ke puskesmas dan beranggapan bahwa pemeriksaan TB di puskesmas memerlukan biaya yang cukup tinggi. Hasil wawancara dengan perawat penanggung jawab program TB di Puskesmas Pasirkaliki mengatakan bahwa selama ini sudah sering dilakukan penyuluhan tentang $\mathrm{TB}$, termasuk tentang anjuran pemeriksaan dahak pada orang kontak serumah, namun 
Herawati : Studi Kasus Ketidakpatuhan Orang Kontak Serumah

orang kontak serumah yang memeriksakan dahak ke puskesmas hanya terdapat beberapa orang saja, dan hal ini berpengaruh terhadap case detection rate (CDR) di Puskesmas Pasirkaliki. Dari uraian di atas, maka tujuan penelitian ini untuk mengidentifikasi faktorfaktor yang menyebabkan orang kontak serumah tidak patuh terhadap anjuran pemeriksaan TB di Puskesmas Pasirkaliki.

\section{Metode Penelitian}

Penelitian ini dilakukan dengan metode studi kasus. Pertimbangan utama pemilihan metode studi kasus adalah keterbatasan kasus TB dengan BTA positif. Partisipan kunci dalam penelitian ini adalah orang kontak serumah dengan penderita TB BTA positif atau dengan anak yang menderita TB yang berada di Kelurahan Pajajaran Kecamatan Cicendo Wilayah Kerja Puskesmas Pasirkaliki. Pada penelitian ini, pengambilan partisipan kunci dilakukan dengan teknik purposive sampling. Jumlah partisipan kunci yang didapatkan pada penelitian ini sebanyak sembilan orang, karena pada jumlah partisipan tersebut telah memberikan data sampai taraf jenuh (saturasi data), sehingga tidak diperlukan penambahan jumlah partisipan atau data baru. Selain partisipan kunci, untuk memperoleh data atau informasi tambahan, peneliti melibatkan partisipan umum, yaitu perawat di Puskesmas Pasirkaliki yang berjumlah enam orang.

Pengumpulan data dilakukan dengan melakukan kunjungan ke alamat yang akan dijadikan calon partisipan sesuai dengan kriteria inklusi, berdasarkan informasi dari Puskesmas Pasirkaliki tentang penderita TB dengan BTA positif atau anak yang menderita TB pada triwulan ke-1 tahun 2011 di wilayah kerja Puskesmas Pasirkaliki, khususnya di Kelurahan Pajajaran. Kemudian peneliti melakukan informed consent, dan menyampaikan juga bahwa identitas partisipan tidak akan terbongkar dan akan dipegang secara teguh.

Pengumpulan data dilakukan dengan beberapa teknik, yaitu dengan studi dokumentasi, observasi pasif, wawancara mendalam, dan diskusi kelompok terarah. Studi dokumentasi dilakukan dengan menganalisis beberapa dokumen, yaitu pedoman tentang pelaksanan $\mathrm{P} 2 \mathrm{~TB}$, laporan tahunan atau bulanan puskesmas, dan pencatatan formulir TB yang ada di Puskesmas Pasirkaliki. Pada observasi pasif tidak berstruktur, peneliti melakukan obsevasi atau pengamatan perilaku perawat dan lingkungan atau kondisi di puskesmas, perilaku partisipan, dan orangorang di sekitar partisipan serta lingkungan fisik tempat tinggal orang kontak serumah. Wawancara mendalam (in-depth interview) dilakukan terhadap orang kontak serumah, kemudian diskusi kelompok terarah atau focus group discussion (FGD) dilakukan pada perawat puskesmas. Proses pengumpulan data dalam penelitian ini dilakukan oleh pewawancara dengan menggunakan pedoman wawancara, alat perekam, kamera digital, dan catatan lapangan.

Analisis data dengan menggunakan model Miles dan Huberman (2007) dengan langkahlangkah yang pertama adalah mereduksi data, merangkum, memilih hal-hal pokok, memfokuskan pada hal-hal yang penting untuk dicari tema, dan polanya. Langkah kedua adalah penyajian data, penyusunan sekumpulan informasi, sehingga memberikan kemungkinan penarikan kesimpulan dan pengambilan tindakan. Langkah ketiga adalah penarikan kesimpulan. Pada langkah ini peneliti memulai mencari arti, mencatat keteraturan pola-pola, penjelasan-penjelasan, alur sebab akibat, dan proposisi.

Keabsahan dan kekuatan ilmiah penelitian ini dilakukan berdasarkan pada empat kriteria yang digunakan, yaitu derajat kepercayaan, derajat keteralihan, derajat kebergantungan dan derajat kepastian. Derajat kepercayaan dalam penelitian ini menggunakan triangulasi yang dilakukan dengan menggabungkan beberapa teknik dalam pengumpulan data dari berbagai sumber data, sehingga sebenarnya peneliti mengumpulkan data yang sekaligus menguji kredibilitas data.

Antisipasi terhadap masalah etik yang muncul dilakukan dengan memberikan penjelasan maksud dan tujuan penelitian pada partisipan. Setelah partisipan menyetujui untuk berpartisipasi dalam penelitian ini, partisipan menandatangani lembar informed consent. Peneliti juga mempertimbangkan prinsip etik dengan memenuhi prinsip the five rights of human subjects in research. 
Herawati : Studi Kasus Ketidakpatuhan Orang Kontak Serumah

\section{Hasil Penelitian}

Hasil penelitian mengenai pengetahuan orang kontak serumah tentang TB meliputi gejala dan penyebab seseorang terkena TB. Pengetahuan tentang gejala orang yang menderita TB adalah batuk-batuk lama, keringat di malam hari, nyeri dada, berat badan menurun, tidak/kurang nafsu makan. Sedangkan penyebab seseorang terkena TB adalah merokok, kedinginan, terlalu capek, stres pemikiran, keturunan, tertular melalui udara dan alat makan/minum. Persepsi kerentanan meliputi perasaan takut tertular, melakukan pemisahan dan menerima takdir.

Persepsi keseriusan tentang penyakit TB adalah kematian dan perasaan malu atau minder. Persepsi mengenai manfaat skrining adalah agar diketahui apakah orang kontak serumah terkena TB atau tidak. Kriteria yang menunjukkan kemampuan orang kontak serumah untuk melakukan pemeriksaan TB adalah pada saat orang kontak serumah sudah merasa sakit atau mengalami gejala-gejala klinistuberkulosis.Perawatmengetahuibahwa salah satu standar P2TB yaitu melakukan pemeriksaan TB pada orang kontak serumah penderita TB paru terutama yang jenis TB paru dengan BTA positif atau TB pada anak. Pemeriksaan TB tersebut dilakukan dengan pemeriksaan dahak sewaktu-pagi-sewaktu (SPS). Persepsi perawat tentang hambatan dalam menjalankan peran dan fungsi sebagai perawat adalah terdapat keterbatasan jumlah tenaga di puskesmas, tingkat pendidikan perawat yang rendah, dan perawat mendapat limpahan tugas di klinik atau di puskesmas.

\section{Pembahasan}

Pengetahuan orang kontak serumah tentang penyakit TB meliputi gejala dari seseorang yang menderita penyakit TB dan penyebab seseorang terkena penyakit TB. Menurut orang kontak serumah bahwa gejala yang diketahui dari anggota keluarganya yang menderita penyakit TB adalah batuk-batuk lama, keringat di malam hari, nyeri dada, wajah pucat, berat badan menjadi menurun atau kurus, dan kurang atau tidak nafsu makan. Berdasarkan gejala-gejala yang telah disebutkan diatas, orang kontak serumah mengetahui bahwa ada anggota keluarganya yang menderita penyakit TB. Hasil penelitian Wejse, dkk. (2008), menyebutkan bahwa gejala-gejala yang ditemukan pada orang yang diduga terkena penyakit $\mathrm{TB}$, antara lain: batuk-batuk lebih dari dua atau tiga minggu, batuk darah, nyeri dada, sesak nafas, anemia, keringat di malam hari serta kehilangan nafsu makan dan berat badan.

Pada tema pengetahuan orang kontak serumah tentang penyebab terkena penyakit $\mathrm{TB}$, partisipan menyatakan tidak mengetahui secara pasti hal yang menyebabkan penyakit $\mathrm{TB}$, sebagian besar partisipan menduga-duga penyebab seseorang terkena penyakit TB yaitu tertular dari orang yang menderita penyakit TB. Penularan tersebut melalui alat-alat makan dan minum. Sebagian partisipan lain menganggap penyebab lain yaitu merokok, terlalu capek secara fisik, stres pemikiran dan terpapar udara dingin. Partisipan menganggap hal-hal tersebut menjadi penyebab TB. Sebagian dari partisipan juga menganggap bahwa seseorang bisa terkena TB akibat keturunan dari generasi sebelumnya. Hasil penelitian tersebut menunjukkan bahwa orang kontak serumah belum mengetahui fakta yang sebenarnya tentang penyebab seseorang tertular TB, partisipan lebih percaya dengan apa yang didapatkan dari masyarakat. Hasil penelitian ini sejalan dengan beberapa penelitian yang lain, diantara adalah penelitian Ayisi, dkk. (2011) di Kenya dan Legesse, dkk. (2010) di Ethiopia. Pada penelitian Legesse, dkk (2010) menyebutkan bahwa beberapa faktor yang dipersepsikan dapat menyebabkan seseorang terkena TB adalah penggunaan alat makan dan minum secara bersama-sama, bekerja terlalu keras, terpapar udara dingin, merokok, serta faktor keturunan. Faktor tersebut dipercaya sebagai faktor yang dapat menyebabkan seseorang terkena TB.

Kurangnya pengetahuan orang kontak serumah tentang penyebab dan cara penularan penyakit TB, bukan disebabkan oleh tidak pernah adanya pemberian informasi atau penyuluhan dari petugas kesehatan atau perawat yang ada di puskesmas, hal ini diakui oleh beberapa orang kontak serumah dan juga disampaikan oleh perawat puskesmas pada FGD. Pengetahuan perawat puskesmas tentang pemeriksaan kontak serumah melalui 
Herawati : Studi Kasus Ketidakpatuhan Orang Kontak Serumah

pemeriksaan dahak, hal ini sudah sesuai dengan prosedur atau standar P2TB. Namun hal ini perlu dilihat lebih jauh mengenai efektivitas penyuluhan kesehatan yang telah dilakukan oleh petugas puskesmas, karena komunikasi penyampaian informasi yang tepat dapat meningkatkan pengetahuan dan pemahaman seseorang, dan merupakan faktor pendorong untuk mengikuti prosedur suatu program (Lewis \& Newell, 2009). Petugas kesehatan seharusnya melihat dan mempertimbangkan faktoryangmemengaruhi keberhasilan penyuluhan kesehatan. Faktor yang memengaruhi keberhasilan penyuluhan kesehatan adalah tingkat pendidikan pada sasaran penyuluhan kesehatan. Pada kasus ini hampir sebagian besar tingkat pendidikan orang kontak serumah yaitu SD dan SMP. Menurut Effendy (1998), tingkat pendidikan dapat memengaruhi cara pandang seseorang terhadap informasi yang baru diterimanya, artinya bahwa semakin tinggi tingkat pendidikan seseorang, maka semakin mudah seseorang menerima informasi yang didapatnya.

Pemberian informasi yang tepat atau pendidikan kesehatan bagi masyarakat, merupakan hal yang penting dalam mengubah perilaku masyarakat, karena pengetahuan mengenai sesuatu hal dapat menyebabkan seseorang melakukan berbagai kegiatan yang berkaitan dengan hal yang diketahuinya itu. Tujuan pendidikan kesehatan adalah untuk mengubah perilaku individu atau masyarakat sehingga sesuai dengan normanorma hidup sehat termasuk dalam hal ini meningkatkan kepatuhan terhadap prosedur P2TB (Carvalho, dkk., 2005).

Persepsi orang kontak serumah dilihat dengan menggunakan kerangka konsep HBM, yang meliputi persepsi kerentanan, persepsi keseriusan atau keparahan, persepsi manfaat, persepsi hambatan dan isyarat tindakan. HBM merupakan teori utama untuk menjadi dasar dalam meneliti tentang skrining (Umeh \& Gibson, 2001). Penggunaan kerangka konsep HBM pada penelitian ini diharapkan dapat mengetahui ketidakpatuhan orang kontak serumah terhadap pemeriksaan TB.

Terkait persepsi orang kontak serumah tentang kerentanan terkena atau tertular TB, sebagian besar partisipan secara tersurat mengatakan bahwa mereka mempunyai perasaan takut tertular penyakit $\mathrm{TB}$ dari anggota keluarga yang menderita TB. Perasaan takut tertular ini menunjukkan bahwa orang kontak serumah meyakini bahwa mereka mempunyai risiko tertular. Partisipan memahami bahwa risiko merupakan suatu bahaya, kehilangan, kerusakan atau ancaman (Zinn, 2008). Adanya perubahan perhatian dari kerentanan menjadi faktor risiko, ini akan menjadi sumber kesehatan seseorang (Dorthe, dkk., 2009).

Persepsi kerentanan dapat ditunjukkan partisipan dengan melakukan pemisahan alat-alat makan dan minum, sikat gigi, tempat tidur, membuat jarak dalam berkomunikasi dan beraktivitas dengan anggota keluarga yang menderita penyakit TB. Kondisi kerentanan yang ditunjukkan oleh partisipan dalam penelitian ini terjadi juga di Sabah Malaysia (Rundi, 2010). Persepsi kerentanan terjadi beberapa faktor diantaranya adalah pengetahuan orang kontak serumah tentang penyebab dan cara penularan TB melalui halhal tadi dan adanya perasaan takut tertular (Dodor \& Kelly, 2009).

Pemisahan yang dilakukan oleh orang kontak serumah terhadap anggota keluarga penderita TB merupakan salah satu indikator terdapat tindakan diskriminasi. Hal ini mengisyaratkan bahwa masih terdapat stigma tentang TB, karena stigma ini yang akan memunculkan diskriminasi (Baral, Karki \& Newel, 2007). Salah satu alasan adanya stigma terhadap penderita TB ini, yaitu adanya perasaan takut tertular (Rie, dkk., 2008; Somma, dkk., 2008).

Orang kontak serumah meyakini bahwa penularan TB yang didapat dari orang kontak serumah merupakan sebuah takdir yang tidak bisa dihindari dan harus diterima. Pemahaman seseorang mengenai takdir yang kurang tepat menyebabkan seseorang bersikap pasrah dan mengganggap bahwa manusia dipaksa untuk menjalani ketentuan dari Tuhan Yang Maha Kuasa (An-Nabhani, 2001). Sakit dianggap sebagai suatu ketentuan dari Tuhan Yang Maha Kuasa, tetapi kondisi sakit juga dipengaruhi oleh tindakan manusia yang bisa mengantarkan pada keadaan sehat atau sakit. Hal tersebut merupakan pilihan manusia itu sendiri. Keyakinan sehat-sakit sebagai sebuah takdir atau ketentuan dari Tuhan merupakan aspek spiritualitas yang terdapat pada diri 
Herawati : Studi Kasus Ketidakpatuhan Orang Kontak Serumah

seseorang (Achir Yani, 2000).

Persepsi keseriusan atau keparahan tentang penyakit $\mathrm{TB}$, hanya sebagian kecil partisipan mengatakan bahwa kondisi terburuk lain yang akan dihadapi oleh orang yang menderita TB yaitu perasaan malu atau minder karena penyakit TB. Perasaan malu atau minder ini dikarenakan stigma masyarakat tentang penyakit TB. Stigma yang berlaku di masyarakat mengenai penyakit TB dipandang sebagai penyakit kotor, penyakit kutukan, dan sering dihubungkan dengan status sosial ekonomi yang rendah (Juniarti \& Evans, 2010).

Hanya sebagian kecil partisipan yang memberikan pernyataan pada saat ditanyakan tentang manfaat dan hambatan pemeriksaan TB. Partisipan menyatakan terdapat manfaat yang didapatkan dari pemeriksaan TB yaitu partisipan dapat mengetahui apakah terkena TB atau tidak. Namun selanjutnya partisipan tersebut mengatakan bahwa dengan diketahuinya seseorang menderita $\mathrm{TB}$, hal tersebut akan membuat partisipan merasa minder karena status baru sebagai seorang yang menderita TB. Perasaan malu atau minder pada penderita TB atau anggota keluarga penderita TB, akan berpengaruh terhadap keberhasilan P2TB. Pengaruh yang teridentifikasi berupa tindakan partisipan yang tidak mau atau terlambat datang ke pelayanan kesehatan untuk melakukan pemeriksaan awal, padahal pemeriksaan ini penting untuk menentukan diagnosis penyakit TB atau melanjutkan program pengobatan (Juniarti \& Evans, 2010).

Pada saat ditanyakan tentang hambatan dalam melakukan pemeriksaan TB, partisipan memberikan pernyataan bahwa dari sisi biaya pemeriksaan, sebagian orang kontak serumah mengetahui pemeriksaan tersebut gratis. Kendala lain yang diungkapkan oleh partisipan adalah tidak ada waktu untuk pengobatan karena partisipan harus bekerja untuk menghidupi keluarga . Hal tersebut menyebabkan partisipan terlambat datang ke puskesmas. Kendala selanjutnya yang diungkapkan partisipan adalah terdapat kesulitan ekonomi atau penghasilan yang memadai. Hal ini menyebabkan orang kontak serumah lebih memprioritaskan bekerja, dibandingkan harus datang ke puskesmas untuk melakukan pemeriksaan TB (Aye, Wyss, Abdualimova, \& Saidaliev, 2010). Kendala yang ditemukan pada perawat puskesmas berdasarkan hasil focus group discusion (FGD) mengenai persepsi perawat tentang kendala yang dirasakan dalam menjalankan peran sebagai tenaga kesehatan yang merawat pasien TB didapatkan terdapat keterbatasan jumlah sumber daya manusia (SDM), pendidikan perawat yang rendah, dan perawat mendapatkan tugas limpahan yang bukan merupakan tugas pokok perawat di puskesmas atau balai pengobatan.

Usaha yang diperlukan untuk meningkatkan profesionalisme perawat saat ini memerlukan dukungan dari berbagai pihak agar perawat puskesmas dapat melaksanakan kegiatan sesuai dengan tugas, tanggung jawab, dan wewenang perawat di puskesmas, balai pengobatan, dan institusi rumah sakit (Depkes, 2006). Usaha yang dapat dilakukan berupa optimalisasi peran perawat kesehatan masyarakat (Perkesmas). Kegiatan perkesmas diharapkan akan menjadi daya ungkit bagi penyelesaian permasalahan TB di masyarakat. Permasalahan utama yang dapat diatasi melalui perkesmas adalah meningkatkan angka cakupan penemuan penderita TB di masyarakat (case detection).

Hampir seluruh partisipan mengatakan bahwa saat ini partisipan merasa dalam keadaan sehat sehingga tidak perlu melakukan pemeriksaan TB. Partisipan akan melakukan pemeriksaan TB apabila sudah merasa sakit yang ditandai dengan gejala-gejala seperti yang partisipan ketahui, diantaranya adalah batuk-batuk lama lebih dari dua minggu, nyeri dada, dan penurunan berat badan. Hal ini menunjukkan bahwa orang kontak serumah akan melakukan pemeriksaan TB, apabila partisipan mempersepsikan sudah mengalami sakit. Hal ini juga terungkap pada saat FGD yang dilaksanakan pada perawat puskesmas. Partisipan FGD menyatakan bahwa masyarakat baru akan datang ke puskesmas jika kondisi sudah sakit parah.

Menurut Allan Young (dalam Kleinman \& Seeman, 2000) bahwa sakit (illness) mengacu pada persepsi seseorang dan pengalaman tertentu secara sosial. Persepsi sakit dibentuk secara budaya (Kleinman, Eisenberg \& Good, 2006). Menurut budaya masyarakat Indonesia 
Herawati : Studi Kasus Ketidakpatuhan Orang Kontak Serumah

bahwa sakit merupakan kondisi yang dapat mengganggu aktivitas, sehingga seseorang tidak bisa menjalankan fungsi dan peran yang seharusnya di masyarakat. Keadaan sehat diartikan sebagai kemampuan untuk menunaikan kewajiban terhadap kehidupan suatu kelompok sesuai dengan dimensi sosial kelompok tersebut. Selama seseorang masih dapat menjalankan kewajiban-kewajiban sosial dan bekerja sesuai peran dan fungsi seseorang, maka masyarakat tidak menganggap sebagai kondisi sakit (Yunindyawati, 2004). Persepsi sehat dan sakit lebih bersifat konsep budaya, oleh karena itu petugas kesehatan dalam hal ini perawat harus bisa melakukan pendekatan pada masyarakat. Perawat juga harus dapat memahami budaya masyarakat setempat. Hal tersebut penting untuk menentukan intervensi yang tepat dan sesuai dimasyarakat tersebut, sehingga derajat kesehatan masyarakat yang optimal dapat tercapai (McFarland, 2006; Purnell \& Paulanka, 2003).

\section{Simpulan}

Penelitian ini menyimpulkan bahwa pengetahuan dan persepsi orang kontak serumah tentang TB masih kurang baik, terdapat stigma mengenai TB di masyarakat, serta terdapat persepsi mengenai hambatan yang dialami perawat dalam mengelola pasien TB. Hal tersebut merupakan alasan yang menyebabkan orang kontak serumah di Kelurahan Pajajaran Kecamatan Cicendo Wilayah Kerja Puskesmas Pasirkaliki tidak patuh terhadap anjuran pemeriksaan TB.

Upaya peningkatan kesehatan diperlukan melalui upaya promotif dan preventif seperti penyuluhan-penyuluhan kesehatan, konseling kesehatan, pengaturan tenaga perawat (perawat komunitas atau perawat keluarga) dalam mengelola programprogram Perkesmas, dan mengaplikasikan pendekatan asuhan keperawatan bio-psikososio-spiritualitas bagi individu, keluarga, kelompok khusus, komunitas, dan masyarakat umum. Upaya tersebut diharapkan dapat menyelesaikan permasalahan kesehatan di masyarakat, terutama untuk meningkatkan deteksi dini TB, pencegahan penularan, dan optimalisasi asuhan keperawatan pada keluarga dengan permasalahan TB.

\section{Daftar Pustaka}

An-Nabhani. (2001). Peraturan hidup dalam islam. Bogor: Pustaka Thoriqul Izzah.

Aye, R., Wyss, K., Abdualimova, H., \& Saidaliev, S. (2010). Household costs of illness during different phases of tuberculosis treatment in Central Asia: A patient survey in Tajikistan. Bio Med Central Public Health, 10(18), 1-8.

Ayisi, J., Anna H., Janet A., Walter M., Peter O., \& Odylia, M. (2011). Care seeking and attitudes towards treatment compliance by newly enrolled tuberculosis patients in the district treatment programme in rural western Kenya: A qualitative study. Bio Med Central Public Health, 11(515), 1-10.

Baral, S. C., Karki, \& Newell. (2007). Causes of stigma and discrimination associated with tuberculosis in Nepal: A qualitative study. Bio Med Central Public Health, 7, 211. doi:10.1186/1471-2458-7-211.

Boon, S. D. \& Verver, S. (2008). Comparison of symptoms and treatment outcomes between actively and passively detected tuberculosis cases: The additional value of active case finding. Journal of Epidemiology Infection Disease, 136, 1342-1349.

Carvalho, A. C. C., Saleri, N., El-Hamad, I., Tedoldi, S., Capone, S., Pezzoli, M. C., ... Matteelli, A. (2005). Completion of screening for latent tuberculosis infection among immigrants. Journal of Epidemiology Infection Disease, 133, 179-185.

Cramm, M., Harry F., Moller V., \& Anna, P. (2010). TB treatment initiation and adherence in a South African community influenced more by perceptions than by knowledge of tuberculosis. Bio Med Central Public Health, 10, 72. doi:10.1186/1471-2458-10-72.

Depkes RI. (2006). Kerangka kerja penanggulangan TB tahun 2006-2010. Jakarta: Depkes.

DepkesRI.(2006).Pedomanpenyelenggaraan upaya kesehatan masyarakat di pusksesmas. Jakarta: Depkes. 
Herawati : Studi Kasus Ketidakpatuhan Orang Kontak Serumah

Depkes RI. (2007). Pedoman nasional penanggulangan $T B$ (Edisi ke-2). Jakarta: Depkes.

Dodor, E.A., \& Kelly, S., (2009). We are afraid of them: Attitudes and behaviours of community members towards tuberculosis in Ghana and implications for TB control efforts. Journal Psychology, Health \& Medicine, 14(2), 170-179.

Dorthe, K. B., Lise D., Torsten L. \& Kirsti M. (2009). "Couldn't you have done just as well without the screening?": A qualitative study of benefits from screening as perceived by people without a high cardiovascular risk score. Scandinavian Journal of Primary Health Care, 9(27), 111-116.

Effendy, N. (1998). Dasar-dasar keperawatan kesehatan masyarakat. Jakarta: EGC.

Gonzalez, E., Brooks J., Matthys F., Caliste P., Armas P., \& Patrick.(2009). Pulmonary tuberculosis case detection through fortuitous cough screening during home visits. Journal Tropical Medicine \& International Health, 14, 131-135.

Juniarti, N., \& Evans, D. (2010). A qualitative review: The stigma of tuberculosis. Journal of Clinical Nursing, 20(13-14), 1961-1970.

Kleinman A., Eisenberg L., \& Good, B. (2006). Culture, illness and care: Clinical lessons from anthropologic and cross-culture research. Ann Intern Med, 88(2), 251-258. doi:10.7326/0003-4819-88-2-251.

Kleinman, A. \& Seeman, D. (2000).Personal experience of illness. Dalam Alrrect, G.L., Fitzpatrick S.R., \& Scrimshaw, S.C. (Eds.), Handbook of Social Studies in Health and Medicine. London: Sage Pub.

Legesse, M., Ameni, G., Mamo, G., Medhin, G., Shawel, D., Bjune, G., \& Abebe, F. (2010). Knowledge and perception of pulmonary tuberculosis in pastoral communities in the middle and lower awash valley of afar region, Ethiopia. Bio Med Central Public Health, 10, 187.

Lewis, C., P., \& Newell, J., N. (2009).
Improving tuberculosis care in low income countries: A qualitative study of patients understanding of "patient support" in Nepal. Bio Med Central Public Health, 9, 190.

Maville, J., A., \& Huerta C., G. (2008). Health promoting in nursing (Edisi ke-2), USA: Thomson Delmar Learning.

McFarlan, M. (2006). Medeline leininger: Culture care theory of diversity and universality. Dalam Tomey, A. M. \&Alligood, M. R. Nursing theorists and their work. St. Louis Missouri: Mosby.

Miles, M., B \& Huberman, A., M. (2007). Analisis data kualitatif: Buku sumber tentang metode-metode baru. Jakarta: UI Press.

Painter, J. E., Christina, P. C., Borba, Hynes, M., Darren, M., \& Glanz, K. (2008). The use of theory in health behaviour research from 2000 to 2005: A systematic review. Annals of Behavioural Medicine, 8(35), 358-362.

Purnell, L. D., \& Paulanka, B. J. (2008). Transcultural health care: A culturally competent approach. USA: F.A Davis.

Rundi, C. (2010). Understanding tuberculosis: Perspectives and experiences of the people of Sabah, East Malaysia. Journal Health Population Nutrition , 28(2), 114-123.

Somma, D., Thomas, B. E., Karim, F., , Kemp, J., Arias, N., Auer, C., ... Weiss, M. G. (2008). Gender and socio-cultural determinants of TB-related stigma in Bangladesh, India, Malawi and Colombia. International Journal Tuberculosis Lung Disease, 12(7), 856-866.

Toth, A., Fackellman J., Piggot, W., \& Tolomeo, O. (2004).Tuberculosis prevention and treatment. Journal Canadian Nurse, 100, 27-30.

Umeh, K., \& Gibson, J. R. (2001). Perceptions of threats, benefits, and barriers in breast self-examination among young asymptomatic women. British Journal of Health Psychology, 2001(6), 361-372.

Rie, A. V., Sengupta, S., Pungrassami, P., 
Herawati : Studi Kasus Ketidakpatuhan Orang Kontak Serumah

Balthip, Q., Choonuan, S., Kasetjaroen, Y., ... Chongsuvivatwong, V. (2008). Measuring stigma associated with tuberculosis and HIV/AIDS in Southern Thailand: Exploratory and confirmatory factor analyses of two new scales. Tropical Medicine and International Health, 13(1), 21-30.

Wejse, C., Gustafson, P., Jens, N., Gomes, V. F., Peter, A., Andersen, P. L., \& Sodemann, M. (2008). TB score: Signs and symptoms from tuberculosis patients in a low-resource setting have predictive value and may be used to assess clinical course. Scandinavian Journal of Infectious Diseases, 40, 111-120.

Yunindyawati. (2004). Modul mata kuliah sosiologi kesehatan. Inderalaya: FISIP Unsri.

Yani, A. (2000). Aspek spiritualitas dalam keperawatan. Jakarta: Widya Medika.

Zinn, C., Vorster, M., \& Sathekge., M.M. (2008). Spinal tuberkulosis evaluated by means of 18F-FDG PET/CT: Pilot study. The Open Nuclear Medicine Journal, 6, 6-11. 